\title{
Introduction: Of Images and Empires
}

In a blog post on a recent trip to a Peruvian monastery, Sara Salem recounts the moment she recognized Andalusian tiles dating from the era of Spanish colonization. Reflecting on this encounter with the lasting material legacy of imperial expansion, she concludes that "[w]e could tell a nice story ... about how art travels and spreads and crosses boundaries; or, we could ask how art comes to be made, by whom, what happened to those artists, and what happened to those who the art was brought to" (Salem 2019). Salem's meditations are timely, indicative of a broader expansion and intensification of conversations about empires, imperialism, and their lasting effects. Today more than ever, all of us-especially those who live in territories that were once epicentres of imperial power-are compelled to re-engage with persisting imperial legacies in a variety of forms and forums, including museums, educational curricula, and geopolitics, to decolonize our imaginaries from the enduring power of empire. This book stems directly from the desire to trouble the legacies of empire. Our goal is twofold: to capture the workings of imperial pasts in the present, and to produce works that challenge empire’s lasting “duress” (Stoler 2016).

We start by asking how to depict empire visually. What images might conjure the political, social, and aesthetic formations of empire? As Jay and Ramaswamy (2014: 4) note, "empire and art-or more broadly, power/knowledge and visual subjectivities-are mutually constituted and entwined, both in the colonies and in 
the metropole". With Jay and Ramaswamy, we contend that empire is both abstract and protean, subject to myriad modulations and embodied in legion avatars. As such, it entails an uncircumscribed multiplicity of images, and can only be understood in the plural. Accordingly, our volume examines imperialism through the visual essay form, which we understand as a series of images juxtaposed with words. With attention to the double friction of pictorial depiction-its limitations in relation to its object(s) and its open-ended viewership(s) - we address two intertwined facets of the relationship between empires and images: imperialism as an ideological project of image-making and images as a means of challenging empires.

Our aim is not simply to intervene in the vast debates within the field of visual culture or to suggest new analytical directions in the study of imperial history and memory. Rather, we seek to make visible the "range of ways" in which empire "helps to constitute social relations" (De Marrais and Robb 2013: 4). Accordingly, this volume presents a variety of visual genres and forms, including photographs, illustrated advertisements, stills from site-specific art performances and films, and maps. A shared ethos and critical commitment span across and unite these different genres: to illuminate the contours of empire's social worlds and its political legacies through the visual essay. This multiplicity of genres and visions is purposeful, as it aims to foster conversation between artistic and academic practice. In doing so, we follow the artistic duo Cooking Sessions, who employ the "visual language, identity, typography and spatial design [developed] for colonial propaganda" to call upon new contributions which "re-present the injustice in imperial legacies" (Cooking Sections 2018: 249). In other words, we approach the social meaning of empire as a historical and contemporary object of memory that is multifaceted and requires not only analytical engagement but re-presentation in a multiplicity of modes. 
Our guiding, titular metaphor, sharpening the haze, captures our commitment to frame empire from different vantage points, seeking focus within its plural modes of power. We contend that one of empire's enduring effects, what Stoler describes as its "duress", is to obscure the very conditions of its own power. The omnipresence of imperial relations on political, economic, social, and cultural levels appears as a haze, a smokescreen that is difficult to peer through. Our task is not to dispel the haze entirely-an impossibility, at any rate-but to sharpen it. By sharpening the haze, we intend to trace empire's effects visually, and to re-present them in ways that subvert and pervert imperial power.

Sharpening the haze is necessarily a multiform task. With Salem (2019) and Benjamin (1969), we insist that images, like works of art, are also works of social production and reproduction. Visual cultures of empire register and speak to imperial power and its constitutive arrangements of bodies, selves, identities, communities, and materials. They are not mere reflections of imperialism, but inherent to the production of empire in the first instance. Like the forces of (re)production behind them, images of empire are manifold-they carry exploitation together with its contradictions, power marked by its limits. We therefore contend that critical scholarship on empires would benefit from more creative attempts to use photography, performance art, mapping, and site-specific interventions to reveal and confront empire.

Our goal is to reclaim a space for the visual in artistic, imaginative, and creative ways that challenge the resonance of empire in the present. As John Tagg has memorably remarked, "Photographs are never evidence of history, they are themselves historical" (1993: 247). ${ }^{1}$ Treating images of empire in their genealogical and historical capacity demands attention to their ongoing effects

1 We thank Zeynep Gürsel for directing us to Tagg's bon mot. 
of knowledge-power in the present. In this sense, our visual essays are partial archives of imperialism as an ideological project of image-making. By the same coin, through the creation of images and art works, we register the deeply asymmetrical relationships that constitute the sociopolitical fibres of empires with subversive intent. In visualizing moments of rupture, flash, and unanticipated uptake, the images we present marshal trenchant arguments against the very powers that produce(d) them. In this spirit, our contributions forward and constitute transgressive re-inscriptions of imperial legacies. By re-presenting the constitutive, frequently violent images of empire, we re-inscribe them with new, counter-hegemonic valences. For us, the question is not just how to "hate [the visual culture of empire] properly" (Jay and Ramaswamy 2014: 14) but also how to attend to the instances in which empire already hates itself in its image. Re-inscription is a means of cultivating attention to empire's latent contradictions. Therefore, it is a guiding conceptual and methodological principle of our collection as a whole, the means to sharpening the imperial haze.

The visual essay as a genre is crucial to our collective aspiration of re-presentation and re-inscription. With its multimodal, visual/verbal character, the visual essay is simultaneously diegetic and mimetic: It tells by showing and shows by telling (Wagner 1979; Grady 1991; Pauwels 1993). In the words of Luc Pauwels, the visual essay embodies "the irreducible expressive and informational power of images, their ability to almost incessantly generate new questions and views, the synergetic strength of combining images and texts ... even in their most basic forms" (Pauwels 2012: 3). From this perspective, these essays constitute one (recent) moment of synergetic strength in the ongoing lives of the photographs, illustrations, stills, maps, and other visual materials that they assemble. Whatever we might say about them "diegetically", the mimetic capacities and effects of visual essays continue to speak for themselves. 
Our authors were asked to assemble ten images and a brief text to illustrate how their art practice and/or academic scholarship might sharpen the imperial haze. As a result, some of the chapters engage empire by integrating images and text, while others allow text and images to work more independently and evocatively. Clearly, and considering the visual nature of this manuscript, texts never aspire to exhaustive description. In this sense, the book must be assessed as an experiment in capturing, disentangling, and undoing empire creatively through images.

Together, the essays engage both empire's power to produce images and images' hold on empire laterally, within the hazy contours of multiple meanings. We seek to sharpen the haze from multiple vantage points, calling upon the dialogic interplay of image and narrative to trouble fixed discourses of imperial pasts through unanticipated re-inscriptions in the present. The words of our contributors offer appropriate metaphors for the results of this method: from the "raw material" of imperial atmospheres we find "worlds in which many worlds fit", images that "activate memories", never fully recoverable in their "battered patinas". If our historicity is imperial and global, then it has also been "transmogrified", "transplanted", and "transformed". Perhaps we may embrace the "delirium" and "discomfort" of such subjectivities, to see the unintended consequences of power, the cataracts of empire's vision.

Sharpening the Haze develops over the course of three sections. We begin with "Representations of Empire", pause to "Dwell in the Haze", and conclude with "Acts of Re-inscription". Broadly, the essays track a course from interrogations of imperial pasts to subversive re-inscriptions of imperial images in the present, even as both projects inform each author's intervention. In "Representations of Empire", we ask how images of empire can reframe imperial pasts and their contemporary legacies. Here, the 
emphasis is on destabilizing the discourses that seek to legitimize and sanitize empire by offering "off-centre" images of imperial pasts. "Dwelling in the Haze" extends the decolonial project of unsettling empire by pointing out how visual representations of imperial pasts are necessarily incomplete, even as they also shelter kernels of counter-imperial logics. Each of the authors in this section, in particular, are attuned to the ways in which a variety of visualizations in the present, ranging from the mimesis of re-enactment to aesthetic distaste for a poor photograph or the banal vistas of real estate brochures, offer hazy insight into imperial continuities, recapitulations, and displacements. Finally, the third section, "Acts of Re-inscription", foregrounds the counter-imperial effects of visual art and archives, ranging from interrogative performance pieces to the unanticipated subversions of colonial-era maps.

"Representations of Empire" offers three distinctive foci that accentuate the persistence of imperial pasts in the present. With Jeremy F. Walton's essay, we begin with an act of unearthing, in which the site of the cemetery serves as a metaphor for the contradictory relegation of empire to the "dead" past and the living force of its present materiality. By taking us on a photographic tour from Thessaloniki and Zagreb to Pula and Styria, Walton traces how, instead of being mere places of decomposition, imperial cemeteries are material archives of now-dead forms of imperial belonging that endure and haunt the present. Next, Nataša Mišković explores how pictorial representation through juxtaposition and intersection can resuscitate imperial commonalities from beyond the grasp of the homogenous nation state. Based

2 Some of the essays published in this volume emerge out of the conference "Empire Off-center", which was organized by the Max Planck Research Group "Empires of Memory: The Cultural Politics of Historicity in Former Habsburg and Ottoman Cities" in November 2018. 
on a large research project at the University of Basel, Mišković's visual archive assembles photographs from large local daily newspapers into a public exhibit featuring the four cities of Sarajevo, Istanbul, Belgrade, and Ankara. Comparing them side by side destabilizes urban narratives of the nation state, while highlighting how the cities' post-Ottoman imperial past persists in the everyday. Finally, Annika Kirbis provokes us to interrogate the visual legacy of the Other as a constitutive figure of empire by contextualizing how "metanarratives of exclusionism" continue to operate in the nation state today. Tracing the persistence and nurturing of the enemy image of the 'Turk' in reference to the Ottoman siege of Vienna, Kirbis explores how certain visual markers still easily trigger and mobilize support for contemporary xenophobic agendas. However, the multiplicity of lived realities a mong Vienna's citizens increasingly disturbs and inverts such exclusive imaginaries of belonging. Together, these three essays represent empire in its "zombie-like" guise, as a resuscitated object whose enduring legacies can be seen not through individual symbols or acts but through the dialogic capacity of multiple images.

Our second section, "Dwelling in the Haze", contributes sets of images that re-engage with imperial narratives to allow for more capacious readings of empire. Guided by Giulia Carabelli, we begin by examining how a 2017 historical re-enactment of the Battle of Solferino (1859), fought between the Habsburgs and the Italian liberation front, can provoke reflections on the contested nature of Italian national identity and rising nationalism. Portraying the agency of atmosphere in charging the sentiments of the re-enactors, Carabelli explores how the after-affects of imperial power figure in the (re)making of collective subjectivities. Through the productive frictions emerging from immediacy, Carabelli traces the possibilities for participants to lay claim to new identities exceeding narratives mediated by 
both imperial and national pasts. Miloš Jovanović pushes us to continue thinking about imperial legacies and the production of subjectivities with a reflective piece on the impossibility of photographing empire in a satisfactory way. Engaging with a discarded visual archive of a research trip to the former Habsburg concession in Tianjin, Jovanović dwells on the discomfort of empire obfuscated in the obstructions, ruptures, and edges of these otherwise unseen photographic failures. Hence, Jovanovićs auto-ethnography turns the impossibility of capturing empire into a productive failure, with its discomforting sentiments as a guiding force in the assemblage of a visual archive. Lastly, by tracing the history of Mangaluru tiles, Ian Cook dwells on the interstices and liminal spaces that escape the strict, neat logics of colonialism and urbanization. Amplifying the entanglements of urban space and exploring layers beyond the surface, Cook's visual essay complicates narratives of empire by portraying its dense, shifting textures. Combining visual archival material and personal photographs with poetry and interviews, Cook engages with assemblage as a method for sharpening imperial haze.

Finally, our third section, "Acts of Re-inscription", courageously pursues the task of re-inscribing imperial legacies through contemporary interventions in the visual field. Sharpening the discomfort of empire, these essays attest to how art practice can become a tool of engagement and resistance to what Ann Stoler has called "imperial duress" (2016). The first two essays by Carla Bobadilla and Deniz Sözen archive site-specific interventions that draw attention to the workings of empire in the everyday, asking us to stop and see what has been neutralized by the normalizing power of empire. In the mi(d)st of Vienna's tropical Butterfly House, Bobadilla turns our attention away from the photogenic butterflies chased by tourist crowds towards the sculptures of indigenous peoples of the Amazon, placed without comment in this staged setting of 'nature'. Critically reflecting on 
such forms of ancestor representation through historical analysis, visual documentation, and artistic intervention, Bobadilla emphasizes the role of performance in the deconstruction of (post)imperial subjects. Drawing on her practice-based research of coffee as a "trans-plant", Sözen further dwells on empire's lasting material and cultural effects on naturecultural worlds. By tracing the intimate connection between empire and coffee along vast (post-)imperial geographies of coffee production, trade, and consumption, Sözen grapples with its multilayered legacies of both rupture and connection, exploitation and exchange, violence and friendship. In the third essay, we accompany film-maker Nina Hoechtl in the process of accounting for her own work on the imperial entailments of race, subjectivity, and performance. Reflecting on Habsburg presence in Mexico, Hoechtl analyses (post-)imperial subjectivities as white delusion (delirio güero) articulated in today's performance of race and class. Hoechtl's visual essay, a set of screenshots from her film of the same name, Delirio Güero, is a tightly woven (audio-) visual assemblage that traces empire in subtle gestures or the consumption of a particular pineapple variety. Finally, in our concluding chapter, Ahmad Barclay confronts us with maps that simultaneously diagram the effects of empire in the past and exemplify how erstwhile empire-making tools can become instruments to condemn imperial desires for territorial expansion in the present. Formerly inaccessible, rare maps of British mandate Palestine that were recently made available for the public by the Israeli National Library serve Barclay as an archive of displacement, bearing witness to colonial domination and expulsion. Based on visual documents of imperial pasts, Barclay's Palestine Open Maps project intervenes in a colonial present offering a possibility for a reckoning against empire.

We envision our assemblage of essays as a point of orientation for future interventions, instead of a summary statement about 
empire and visual culture. We have gestured to a hazy formation of power and knowledge, which we can only sharpen through resolute refusal to draw univocal conclusions. Considering how the power of (and urge for) closure resonates with imperial logics and imperatives, the book is left intentionally without a concluding section. We do not claim to have demarcated and domesticated a discursive territory. Rather, the visual essays of Sharpening the Haze are an opening salvo and a continued call for re-inscription.

\section{Acknowledgements}

We thank the anonymous peer-reviewers for their timely and constructive feedback. Their work has helped us in revising parts of the book for publication.

\section{References}

Benjamin, Walter. 1969. Illuminations. Harry Zohn, trans. New York: Schocken Books.

Cooking Section (Daniel Fernández Pascual and Alon Schwabe). 2018. The Empire Remains Shop. New York: Columbia University Press.

DeMarrais, Elizabeth and John Robb. 2013. "Art Makes Society: An Introductory Visual Essay". World Art 3(1):3-22.

Grady, John. "The Visual Essay and Sociology". Visual Sociology 6, no. 2 (1 September 1991): 23-38. https://doi. org/10.1080/14725869108583689.

Jay, Martin, and Sumathi Ramaswamy, eds. 2014. Empires of Vision: A Reader. Objects/Histories. Durham, NC: Duke University Press,

Pauwels, Luc. "The Visual Essay: Affinities and Divergences between the Social Scientific and the Social Documentary Modes". Visual Anthropology 6, no. 2 (1 January 1993): 199-210. 
Pauwels, Luc. “Conceptualising the 'Visual Essay' as a Way of Generating and Imparting Sociological Insight: Issues, Formats and Realisations". Sociological Research Online 17, no. 1 (1 February 2012): 1-11. https://doi.org/10.5153/sro.2575. https://doi.org/10. 1080/08949468.1993.9966615.

Salem, Sara. 2019. "Traveling Tiles, Traveling Empires”. [Blog] Available at https://neocolonialthoughts.wordpress.com.

Stoler, Ann Laura. 2016. Duress. Imperial Durabilities in Our Times. Durham, NC: Duke University Press.

Tagg, John. 1993. The Burden of Representation: Essays on Photographies and Histories. Minneapolis, MN: University of Minnesota Press.

Wagner, Jon. 1979. Images of Information: Still Photography in the Social Sciences. Beverly Hills, CA: Sage Publications. 